\title{
Quantificação dos depósitos da pulverização em função da técnica de aplicação na cultura da soja
}

Quantification of spray deposits according to the application technique in soybean crop

Cuantificación de los depósitos de la pulverización en función de la técnica de

aplicación en el cultivo de la soja

Pedro Hideki Omoto

Discente do curso de Engenharia Agronômica, FCAT - UNESP, Brasil

pe_omoto19@hotmail.com

Rafael Simões Tomaz

Professor Assistente Doutor, FCAT - UNESP, Brasil

rafaelst@dracena.unesp.br

Evandro Pereira Prado

Professor Assistente Doutor, FCAT - UNESP, Brasil

epprado@dracena.unesp.br 


\section{RESUMO}

O conhecimento e uso da melhor técnica de aplicação de defensivos podem maximizar a eficiência de controle e reduzir contaminação ambiental. O trabalho teve como objetivo avaliar o desempenho de pontas de pulverização (jato cônico - TXA 8002 VK, plano duplo - TTJ 60 11002, plano com indução de ar - AIXR 110025, plano duplo de deriva reduzida - DGTJ 11002 e jato plano de faixa ampliada - XR 8003) sobre os depósitos da pulverização em três partes de amostragem das plantas de soja (superior, mediano e inferior) nos estágios V7-8 e R3. O ensaio foi realizado na Faculdade de Ciências Agrárias e Tecnológicas - UNESP - Câmpus de Dracena. Para detecção dos depósitos da pulverização foi realizada a aplicação do corante alimentício Azul Brilhante na concentração de 1500 $\mathrm{mg} \mathrm{L}^{-1}$. Valores médios dos depósitos foram submetidos à análise de variância em esquema fatorial e as médias comparadas pelo teste de Students (LSD) a $5 \%$ de probabilidade. As frequências acumuladas dos dados originais de deposição foram adequadamente ajustadas segundo modelo de Gompertz. No estádio de desenvolvimento V7-8 a ponta de pulverização que proporcionou maior valor de deposição nas plantas de soja foram TTJ 60, DGTJ 11002 e XR 8003. Na segunda aplicação (R5), as pontas de pulverização que proporcionaram os maiores valores de deposição nas plantas de soja foram AIXR 110025, TXA 8002 e DGTJ 110025. Maiores valores de uniformidade nas folhas da parte mediana das plantas foram verificadas pela ponta DGTJ 11002 nos estágios V7-8 e R5.

Palavras-chave: deposição da pulverização, tecnologia de aplicação, pontas hidráulicas.

\section{ABSTRACT}

The knowledge and use of the most efficient application technique may maximize the performance of pesticides and reduce environmental contamination. In order to verify the best techniques of pesticide application this research aimed evaluate spray nozzles (Hollow cone spray - TXA 8002 VK, Twin flat spray - TTJ 60 11002, Air induction flat spray - AIXR 110025, Drift guard twin flat spray - DGTJ 11002 and Extended range flat spray - XR 8003) on soybean leaves spray deposits (top, middle and bottom) in V7-8 and R3 stages. The experiment was carried out at the College of Technology and Agricultural Science - UNESP - Dracena - Campus. To detect the spray deposits, it was used the Brilliant blue dye applied at concentration of $1500 \mathrm{mg} \mathrm{L}^{-1}$. Mean values of the deposits were submitted to analysis of variance in a factorial scheme and the means compared by the Students (LSD) test at $5 \%$ probability. The accumulated frequencies of the original deposition data were adjusted according to the Gompertz model. At the V7-8 soybean development stage the spray nozzle that provided the highest deposition nozzle which provided the highest deposition values in the soybean plants were AIXR 110025, TXA 8002 and DGTJ 110025. Larger uniformity values in the leaves of the middle part of the plants were verified by the spray nozzle DGTJ 11002 on both stages V7-8 and R5.

Keywords: spray deposition, application technology, hydraulic nozzles.

\section{RESUMEN}

El conocimiento y uso de la técnica de aplicación más eficiente pueden maximizar la eficiencia de los defensivos agrícolas y reducir la contaminación ambiental. Con el fin de verificar las mejores técnicas de aplicación de productos fitosanitarios el trabajo ha tenido como objetivos evaluar boquillas de pulverización (cónico - TXA 8002 VK, plano doble - TTJ 60 11002, plano con inducción de aire - AIXR 110025, plano doble de deriva - DGTJ 11002 y plano de banda ampliada - XR 8003) sobre los depósitos de la pulverización en tres posiciones de muestreo de las plantas de soja (inferior, mediana y superior) en las etapas V7-8 y R3. Los ensayos se realizaron en la Facultad de Ciencias Agrarias y Tecnológicas - UNESP - Câmpus de Dracena. Para la detección de los depósitos de la pulverización se realizó la aplicación del colorante alimenticio Azul Brillante en la concentración de $1500 \mathrm{mg} \mathrm{L}^{-1}$. Los valores medios de los depósitos se sometieron al análisis de varianza en esquema factorial y las medias comparadas por el test LSD al 5\% de probabilidad. Las frecuencias acumuladas de los datos originales de deposición se ajustaron adecuadamente según el modelo de Gompertz. En la fase de desarrollo V7-8 la boquilla de pulverización que proporcionó mayor valor de deposición en las plantas de soja fueron TTJ 60, DGTJ 11002 y XR 8003 . En la segunda aplicación (R5), las boquillas de pulverización que proporcionaron los mayores valores de deposición en las plantas de soja fueron AIXR 110025, TXA 8002 y DGTJ 110025. Los valores de uniformidad en las hojas de la parte mediana de las plantas se verificaron por la boquilla DGTJ 11002 en los estadios V7-8 and R5.

Palabras- clave: deposición de la pulverización, tecnología de aplicación, boquillas hidráulicas. 


\section{INTRODUÇÃO}

A soja constitui um dos produtos agrícolas de maior relevância para a economia brasileira e possivelmente uma das culturas que apresentaram crescimento mais expressivo no cultivo e no segmento agroindustrial, na segunda metade do século XX, no Brasil (BARBOSA; ASSUMPÇÃO, 2001). O cultivo dessa leguminosa está sujeita ao ataque de pragas desde a germinação até a colheita (DEGRANDE et al., 2012) além do ataque de diversos patógenos. Portanto, o domínio da tecnologia de aplicação de defensivos agrícolas mostra-se fundamental para o aumento da eficiência do produto aplicado e a diminuição da contaminação do aplicador e do ambiente, bem como para a redução dos custos nas aplicações (BAUER; PEREIRA, 2005).

Na maioria das vezes, dá-se muita importância ao defensivo agrícola a ser aplicado e pouca à técnica de aplicação. Não basta conhecer o produto a ser aplicado, também é fundamental conhecer a forma de aplicação (CUNHA et al., 2003).

A deposição das gotas sobre o alvo a ser controlado é complexa e pode afetar a eficácia de produtos fitossanitários. A interação entre os parâmetros da aplicação como, por exemplo, tamanho das gotas produzidas, assim como a sua distribuição pelo alvo e a cobertura, são fatores pouco estudados e que podem ter influência no controle, dependendo do tipo de herbicida utilizado e das características físico químicas do alvo a ser tratado (RUAS et al., 2011).

Segundo Cunha et al. (2008), a cobertura do dossel da soja, proporcionada pela aplicação de fungicida, em geral é baixa, principalmente nas folhas da parte inferior da planta, resultando, em muitos casos, no controle ineficiente de doenças como a ferrugem asiática (Phakopsora pachyrhizi) e o mofo branco (Sclerotinia sclerotiorum), os quais iniciam o processo de infecção nas folhas da parte inferior da planta. Por essa razão, as aplicações precisam vencer a barreira imposta pela massa de folhas e, assim, promover boa cobertura no interior do dossel da planta (Ozkan et al., 2006).

A utilização apropriada de pontas de pulverização, que proporcionem cobertura homogênea com espectro de gotas uniforme, é importante no processo de aplicação de defensivo agrícola. Assim, o estudo do espectro de gotas produzidas pelas pontas de pulverização assume grande importância na eficiência de aplicação de produtos fitossanitários (CUNHA; TEIXEIRA, 2001).

Neste contexto, a seleção correta das pontas de pulverização pode incrementar a qualidade da aplicação. Esses elementos são considerados um dos principais componentes da pulverização, pois conferem características como tamanho de gota, distribuição da calda e vazão, promovendo maior segurança e efetividade no controle de pragas, doenças e plantas daninhas (Viana et al., 2010).

Cunha et al. (2011), no entanto, mostraram que, mesmo usando-se diferentes tipos de pontas de pulverização, permanece a dificuldade de se atingir as folhas situadas na parte inferior da planta da soja e que nenhuma das pontas estudadas por esses autores não proporcionaram elevadas valores de deposição nessa região da planta. PRADO, E.P. (2015) também mostrou que a menor quantidade de calda retida nas folhas da parte inferior das plantas é uma característica não desejada, quando um produto fitossanitário é recomendado para o controle 
de doenças que se iniciam nessa parte das plantas. Alternativas visando ao aumento dos depósitos da pulverização devem ser estudadas em virtude de se obter pulverizações de defensivos mais eficazes.

Diversas características quanto à distribuição e espectro de gotas encontram-se disponíveis nos acessórios de pulverização que o mercado oferece, tais como, as pontas hidráulicas (BAUER et al., 2006), as quais podem possibilitar pulverização eficiente em diferentes tipos de alvos a serem atingidos. A escolha da ponta de pulverização que possibilita a melhor deposição das gotas no alvo biológico desejado é essencial para a maximização da eficiência de controle.

De acordo com Fritz et al. (2012), o tamanho das gotas é um fator decisivo na deposição tanto dentro como fora do alvo. De fato, este parâmetro é de notória importância na tecnologia de aplicação por ser um dos principais fatores relacionados com a perda de fitossanitários para o ambiente. Gotas finas podem aumentar a cobertura em pulverizações e com isto a eficácia dos produtos (Derksen et al., 2007). Gotas grossas são menos propensas à evaporação e carreamento pelo vento sendo, porém, mais sujeitas a não se fixarem no alvo e escorrerem para o solo (Cunha et al., 2006; Czaczyk et al., 2012).

Visto a grande importância da cultura da soja para o agronegócio brasileiro e que pulverizações de defensivos agrícolas ainda é a medida mais eficiência e, em muitos casos, a única alternativa de controle de insetos-pragas e doenças, pesquisas que busquem a maximização da eficiência de controle desses agentes torna-se relevante. Vale lembrar que a tecnologia de aplicação visa também à diminuição do impacto ambiental que os defensivos podem proporcionar caso não sejam aplicados adequadamente. Dessa forma, o emprego de técnicas que busquem maior eficiência no processo de aplicação e ao mesmo tempo a redução das perdas de defensivos ocasionadas por deriva é fundamental para realização de uma agricultura mais sustentável.

\section{OBJETIVOS}

A pesquisa teve como objetivo avaliar a eficácia de diferentes pontas de pulverização sobre os depósitos da pulverização no estádio vegetativo (V7-8) e reprodutivo (R5) da cultura da soja.

\section{METODOLOGIA}

\section{Características gerais do ensaio}

O experimento foi conduzido na Faculdade de Ciências Agrárias e Tecnológicas da UNESP Câmpus de Dracena. A variedade utilizada foi a Coodetec CD 2728 Ipro espaçada em 0,45 m e densidade de 18 sementes $\mathrm{m}^{-1}$ que proporcionou uma população de aproximadamente 270.000 plantas por hectare. A variedade foi escolhida por se adaptar bem nas condições onde foram realizados os ensaios. Foi realizada adubação de semeadura na quantidade de $300 \mathrm{~kg}$ ha ${ }^{-1}$ do formulado 082816 . O sistema de semeadura foi do tipo direto no solo com auxílio de irrigações complementares por aspersão. A semeadura foi realizada no dia 15/12/16 e estabelecida a emergências das plântulas no dia 26/12/16. 


\section{Delineamento experimental do ensaio de pontas de pulverização}

$O$ ensaio foi conduzido no delineamento experimental em blocos casualizados com 5 tratamentos e 4 repetições em esquema fatorial $5 \times 3$ (pontas de jato cônico - TXA 8002, jato plano - XR 8003, jato plano duplo - TTJ 60, jato plano com indução de ar - XR 110025, plano duplo - DGTJ 11002) em três posições de amostragem da planta (inferior, mediana e superior). Cada parcela constou de $3 \mathrm{~m}$ de largura por $7 \mathrm{~m}$ de comprimento. As pulverizações foram realizadas através de pulverizador pesquisa $\left(\right.$ Herbicat $^{\circledR}$ ) pressurizadas por $\mathrm{CO}_{2}$ equipados com 6 pontas espaçadas em $0,5 \mathrm{~m}$. Todos os ensaios foram aplicados com o mesmo volume de aplicação, apresentando-se com $210 \mathrm{~L} \mathrm{ha}^{-1}$. Os tratamentos foram aplicados quando as plantas estavam no estágio vegetativo (V7-V8) e reprodutivo (R5) de acordo com as escala proposta por Fehr et al., (1971). As condições ambientais foram monitoradas no momento da pulverização conforme auxílio de um Termo-higro-anemômetro digital portátil (modelo THAL300). A Tabela 1 descreve os tratamentos utilizados. Ressalta-se que todos os tratamentos foram realizados com o mesmo volume de aplicação a fim de analisar apenas a deposição de calda em função do tipo de pontas.

Tabela 1. Descrição dos tratamentos para utilizados no ensaio de deposição em folhas de soja.

\begin{tabular}{ccccc}
\hline Marca & $\begin{array}{c}\text { Pressão } \\
\text { (bar) }\end{array}$ & $\begin{array}{c}\text { V.A. } \\
\text { (L ha } \mathbf{~}^{-1} \text { ) }\end{array}$ & Modelo das pontas & $\begin{array}{c}\text { Tamanho de } \\
\text { gota }^{\mathbf{a}}\end{array}$ \\
\hline TXA 8002 VK & 4 & 210 & Cônico & Fina \\
TTJ 60 11002 & 4 & 210 & Plano duplo & Média \\
AIXR 110025 & 2,4 & 210 & Plano com indução de ar & Muito grossa \\
DGTJ 11002 & 4 & 210 & Plano duplo de deriva reduzida & Fina \\
XR 8003 & 1,8 & 210 & Plano de faixa ampliada & Média \\
\hline
\end{tabular}

${ }^{\mathrm{a}}$ Tamanho de gota de acordo com fabricante.

V.A.: Volume de aplicação.

\section{Quantificação dos depósitos da pulverização}

Após a aplicação da calda contendo o corante Azul Brilhante e secagem das plantas, 10 amostras (cada amostra composta por 5 folhas de soja) da parte superior, mediana e inferior das plantas de soja foram coletadas e acondicionadas em sacos plásticos e em seguida levadas ao laboratório, onde foram lavadas com 100 e $200 \mathrm{~mL}$ de água deionizada, respectivamente no estádio V7-8 e R5, para remoção do corante.

Com a lavagem e retirada do excesso de líquido, as amostras foram colocadas em sacos de papel previamente etiquetados e levadas a uma estufa de circulação e renovação de ar (TE $394 / 3$ ), para secagem. Após 72 horas, a uma temperatura de $65^{\circ} \mathrm{C}$, as amostras foram retiradas e pesadas, determinando-se a massa seca (MS) em balança analítica. A quantidade do corante depositada nas amostras foi quantificada em espectrofotômetro (Bioespectro modelo SP 220) com comprimento de onde $630 \mathrm{~nm}$ (SCUDELER et al., 2004). Com as concentrações prévias já conhecidas do corante de 10,$0 ; 5,0 ; 2,5 ; 1,25 ; 0,625$ e $0,15625 \mathrm{mg} \mathrm{L}^{-1}$ foi determinado a equação de reta linear que permitiu transformar os valores de absorbância em concentração 
do corante $\left(\mathrm{mg} \mathrm{L}^{-1}\right)$. De posse dos valores de concentração do corante na calda, concentração do corante na amostra ( 5 folhas) e volume de diluição da amostra foi possível estabelecer o volume capturado pelo alvo através da equação: $V_{1}=\left(C_{2} x \cdot V_{2}\right) / C_{1}$, em que: $V_{1}=$ volume retido pelo alvo $(\mathrm{mL}) ; \mathrm{C}_{2}=$ concentração detectada no espectrofotômetro $\left(\mathrm{mg} \mathrm{L}^{-1}\right) ; V_{2}=$ volume de diluição da amostra de cada planta $(\mathrm{mL})$ e $\mathrm{C}_{1}=$ concentração inicial na calda de aplicação $(\mathrm{mg} \mathrm{L}$ ${ }^{1}$ ). O volume retido em cada amostra em $\mathrm{mL}$ foi dividido pela sua respectiva massa seca, obtendo-se assim a quantidade em $\mathrm{mL} \mathrm{g}^{-1}$ de MS.

\section{Análise dos dados}

Os valores dos depósitos da pulverização nas plantas foram submetidos à análise de variância em esquema fatorial e as médias comparadas pelo teste de Students (LSD) a $5 \%$ de probabilidade. Os dados obtidos dos depósitos em porcentagem foram ajustados pelo modelo de Gompertz, $\quad F=e^{a-e^{(-b-c * X)}}$, para representar as frequências acumuladas (F) da deposição da calda pulverizada em porcentagem. Adotou-se o valor inicial 4,60517 para o parâmetro " $a$ " do modelo, o qual representa a assíntota máxima da curva, em que $e^{a}=100$. O deslocamento da curva ao longo do eixo x é representado pelo módulo do parâmetro " $a$ ", e a inclinação ou concavidade da curva em relação à frequência acumulada, pelo parâmetro " $c$ ". Por fim, para melhor visualização, optou-se por apresentar as frequências não-acumuladas (FN) que correspondem à derivada da primeira do modelo, de forma que $F N=c$ * $e^{\left(a-b-c * X-e^{-b-c * X}\right)}$. De acordo com Velini (1995), as frequências acumuladas e nãoacumuladas do modelo de Gompertz permitem a interpretação biológica dos resultados. Os ajustes das curvas de crescimento, para cada ponta de aplicação e para cada parte da planta, as figuras foram realizados por meio de rotinas desenvolvidas pelos autores nos programa livre $R$ ( $R$ Core Team, 2016).

\section{RESULTADOS E DISCUSSÕES}

Os dados ambientais no momento da aplicação dos tratamentos no estádio de desenvolvimento V7-8 da soja foram: umidade relativa do ar de $55 \pm 5 \%$, temperatura de $32 \pm$ $3{ }^{\circ} \mathrm{C}$ e velocidade do vento de $6,6 \pm 2 \mathrm{~km} \mathrm{~h}^{-1}$. A análise de variância foi significativa para as variáveis pontas de pulverização $(F=4,5 ; P=0,0014)$, posição de amostragem ( $F=187,7$; $\mathrm{P}<0,0001)$ e a interação ponta de pulverização x posição de amostragem $(F=3,3 ; P=0,0009)$. Na Tabela 2 são descritos os valores de deposição em função de diferentes pontas de pulverização e parte de amostragem nas plantas de soja no estádio de desenvolvimento da cultura V7-8. 


\section{da Alta Paulista}

Tabela 2. Médias dos depósitos da pulverização em função da ponta de pulverização e parte de amostragem das plantas de soja no estádio de desenvolvimento V7-8.

\begin{tabular}{ccccccc}
\hline Parte da & \multicolumn{5}{c}{ Pontas de pulverização $\left(\boldsymbol{\mu \mathrm { g } ^ { - 1 } \mathrm { MS } )}\right.$} & \\
\cline { 2 - 6 } planta & AIXR 110025 & TXA 8002 & DGTJ 11002 & TTJ 60 & XR 8003 & Média \\
\hline Superior & 177.9 a C & 207.4 a B & 220.9 a B & 259.4 a A & 230.0 a B & 219.1 a \\
Mediana & $148.6 \mathrm{~b} \mathrm{~A}$ & $143.3 \mathrm{~b} \mathrm{~A}$ & $155.1 \mathrm{~b} \mathrm{~A}$ & $144.6 \mathrm{~b} \mathrm{~A}$ & $147.0 \mathrm{~b} \mathrm{~A}$ & $147.7 \mathrm{~b}$ \\
Inferior & $100.5 \mathrm{c} \mathrm{A}$ & $109.0 \mathrm{c} \mathrm{A}$ & $109.8 \mathrm{c} \mathrm{A}$ & $112.6 \mathrm{c} \mathrm{A}$ & $110.4 \mathrm{c} \mathrm{A}$ & $108.5 \mathrm{c}$ \\
Média & $142.4 \mathrm{C}$ & $153.2 \mathrm{BC}$ & $162.0 \mathrm{AB}$ & $172.2 \mathrm{~A}$ & $162.4 \mathrm{AB}$ & \\
\hline
\end{tabular}

Médias seguidas de mesma letra minúscula na coluna e maiúscula na linha não diferem entre si pelo teste LSD ( $p<$ $0,05)$.

Verifica-se na Tabela 2 que a ponta de pulverização TTJ 60 apresentou maior valor de deposição de calda nas folhas de soja da parte superior da planta diferenciando significativamente das demais pontas. A ponta AIXR 110025 proporcionou o menor valor médio de deposição diferenciando significativamente das demais pontas.

Já nas folhas da parte mediana da soja não ocorreu diferenças significativas dos valores de deposição entre as pontas de pulverização. Da mesma forma, não foi verificado diferença significativa nos valores de deposição entre as pontas de pulverização nas folhas da parte inferior das plantas (Tabela 2).

Diferenças significativas foram encontradas entre as médias de deposição da calda comparando as posições de amostragem da planta (inferior, mediano e superior) para todas as pontas de pulverização testadas (Tabela 2). As folhas da parte superior da planta de soja receberam os maiores valores de deposição de calda, seguida pelas folhas da parte mediana e inferior.

Comparando as médias de deposição de calda das diferentes pontas de pulverização, verificase que a ponta TTJ 60 apresentou o maior valor de deposição de calda, porém não diferenciaram significativamente das pontas XR 8003 e DGTJ 11002. A ponta AIXR 110025 foi a que apresentou menor média de deposição na planta de soja, diferindo significativamente das demais pontas.

No momento da aplicação realizada no estádio de desenvolvimento da cultura R5 as condições climáticas foram: umidade relativa do ar de $60 \pm 3 \%$, temperatura $29 \pm 3{ }^{\circ} \mathrm{C}$ e velocidade do vento de $5 \pm 2 \mathrm{~km} \mathrm{~h}^{-1}$. A análise de variância foi significativa para as variáveis pontas de pulverização ( $F=26 ; P=0,027)$, posição de amostragem ( $F=70,2 ; P<0,0001)$ e não significativa para interação ponta de pulverização x posição de amostragem ( $F=1,7 ; P=0,0982)$. Na Tabela 3 são descritos os valores de deposição em função de diferentes pontas de pulverização e parte de amostragem nas plantas de soja no estádio de desenvolvimento da cultura R5. 
Tabela 3. Médias dos depósitos da pulverização em função da ponta de pulverização e parte de amostragem das plantas de soja no estádio de desenvolvimento R5.

\begin{tabular}{ccccccc}
\hline \multirow{2}{*}{$\begin{array}{c}\text { Parte da } \\
\text { planta }\end{array}$} & \multicolumn{5}{c}{ Pontas de pulverização $\left(\mu \mathrm{L} \mathrm{g}^{-1} \mathrm{MS}\right)$} \\
\cline { 2 - 6 } & AIXR 110025 & TXA 8002 & DGTJ 11002 & TTJ 60 & XR 8003 & Média \\
\hline Superior & 118.4 a A & 128.9 a A & 120.7 a A & 103.8 a A & 107.0 a A & 115.8 a \\
Mediana & 101.0 a A & $91.6 \mathrm{~b} \mathrm{~A}$ & $79.0 \mathrm{~b} \mathrm{~A}$ & $77.8 \mathrm{~b} \mathrm{~A}$ & $80.0 \mathrm{~b} \mathrm{~A}$ & $85.9 \mathrm{~b}$ \\
Inferior & $69.2 \mathrm{~b} \mathrm{~A}$ & $54.8 \mathrm{c} \mathrm{A}$ & $71.2 \mathrm{~b} \mathrm{~A}$ & $54.2 \mathrm{c} \mathrm{A}$ & $72.6 \mathrm{~b} \mathrm{~A}$ & $64.4 \mathrm{c}$ \\
Média & $96.2 \mathrm{~A}$ & $91.8 \mathrm{AB}$ & $90.3 \mathrm{AB}$ & $78.6 \mathrm{~B}$ & $86.5 \mathrm{AB}$ & \\
\hline
\end{tabular}

Médias seguidas de mesma letra minúscula na coluna e maiúscula na linha não diferem entre si pelo teste LSD ( $p<$ $0,05)$.

Assim como na aplicação realizada em V7-8, verificou-se diferença significativa entre as médias de deposição de calda comparando as partes de amostragem da planta (inferior, mediana e superior). Folhas da parte superior receberam os maiores valores de deposição de calda, seguida pela parte mediana e inferior da planta (Tabela 3).

Comparando as médias de deposição de calda das diferentes pontas de pulverização verificase que a ponta AIXR 110025 proporcionou os maiores valores de deposição de calda diferenciando significativamente da ponta TTJ 60 que apresentou os menores valores médios de deposição (Tabela 3). Os maiores valores de deposição de calda, em ambos os estádios de aplicação, foram registrados nas folhas da parte superior da planta da soja. Isso ocorre devido ao chamado "efeito guarda-chuva" em que as folhas da parte superior da planta formam uma barreira que dificulta a penetração das gotas de serem depositadas na parte mediana e inferior da planta ocasionado desuniformidade na deposição ao longo do dossel da cultura.

Maiores valores de deposição foram verificados na aplicação realizada no estádio V7-8 das plantas de soja comparada com os valores de deposição no estádio R5. Essa redução dos depósitos da pulverização nas plantas em estádios mais avançados provavelmente esta relacionado com os maiores índice de área foliar das plantas de soja. Assim como ocorrido nessa pesquisa, Gazziero et al. (2006) reportaram que os depósitos da pulverização em plantas de soja reduziram conforme o de desenvolvimento das plantas. O aumento dos depósitos da pulverização pode proporcionar maior eficiência de controle visto a maior quantidade da molécula do defensivo na superfície a ser tratada. Tomando como exemplo a ferrugem asiática da soja, aplicação realizada no estádio V7-8 receberia maior quantidade de fungicidas ao longo do dossel da planta (folhas da parte superior, mediana e inferior) comparada com a aplicação realizada no estádio $\mathrm{R} 5$.

As Tabelas 4 e 5 apresentam as estimativas dos parâmetros das frequências acumuladas dos depósitos da pulverização nas folhas de soja da parte superior, mediana e inferior obtidas pelo modelo de Gompertz e nas Figuras 1 e 2 a representação das frequências acumuladas e não acumuladas em função dos depósitos da pulverização proporcionadas por diferentes pontas de pulverização. De acordo com Farinha et al.(2009) o uso do modelo de Gompertz permite, a partir da análise das frequências acumuladas e não acumulada, identificar as pontas de maior uniformidade na distribuição dos depósitos, segundo o grau de curtose (concavidade) da curva. 
Tabela 4. Resultados das análises de regressão das frequências acumuladas dos depósitos da pulverização no estádio V7-8 proporcionados pelas pontas de pulverização, utilizando ajuste do modelo de Gompertz.

\begin{tabular}{lccccc}
\hline Parâmetro da & AIXR 110025 & TXA 8002 & DGTJ 11002 & TTJ 60 & XR 8003 \\
\cline { 2 - 6 } Equação & \multicolumn{5}{c}{ Parte superior da planta } \\
\hline a & 4,73 & 4,67 & 4,69 & 4,66 & 4,72 \\
b & $-1,98$ & $-3,68$ & $-3,46$ & $-3,2$ & $-3,92$ \\
c & 0,012 & 0,019 & 0,017 & 0,014 & 0,018 \\
$\mathrm{R}^{2}$ & 0,99 & 0,99 & 0,99 & 0,99 & 0,99 \\
\hline \multicolumn{5}{c}{ Parte mediana da planta } \\
\hline a & 4,7 & 4,68 & 4,69 & 4,65 & 4,7 \\
b & $-3,0$ & $-2,31$ & $-3,37$ & $-1,92$ & $-2,96$ \\
c & 0,022 & 0,018 & 0,024 & 0,015 & 0,022 \\
$\mathrm{R}^{2}$ & 0,99 & 0,99 & 0,99 & 0,99 & 0,99 \\
\hline \multicolumn{5}{c}{ Parte inferior da planta } \\
\hline a & 4,67 & 4,69 & 4,66 & 4,72 & 4,68 \\
b & $-1,52$ & $-1,7$ & $-1,49$ & $-1,21$ & $-1,47$ \\
c & 0,018 & 0,018 & 0,016 & 0,013 & 0,016 \\
$\mathrm{R}^{2}$ & 0,99 & 0,99 & 0,99 & 0,99 & 0,99 \\
\hline
\end{tabular}

Maior uniformidade de depósitos da pulverização nas folhas da parte superior das plantas foi verificada para a ponta de jato cônico TXA 8002 o qual pode ser observada pela menor concavidade da curva e pelo maior valor do parâmetro " $c$ " $(0,019)$. Já a ponta com indução de ar AIXR 110025 foi a que apresentou menor uniformidade de distribuição evidenciada pelo menor valor do parâmetro " $c$ " $(0,012)$. Nas folhas da parte mediana da soja maiores valores de uniformidade de deposição foram atribuídos para a ponta DGTJ 60 com maior valor de parâmetro " $c$ " $(0,024)$ comparada com as demais pontas. Já a ponta TTJ 60 foi a que apresentou menor uniformidade com valores de 0,012 do parâmetro " $c$ " (Figura 1 e Tabela 4). Nas folhas da parte inferior os depósitos da pulverização entre as pontas foram mais uniformes, evidenciado pela menor variação dos valores de parâmetro "c" (Tabela 4). 
Figura 1. Frequência acumulada e não acumuladas dos depósitos da pulverização ( $\mu \mathrm{L} \mathrm{g}^{-1} \mathrm{MS}$ ) proporcionados por diferentes pontas de pulverização nas folhas de soja da parte superior, mediana e inferior no estádio V7-8. AIXR 110025 (preto); DGTJ 11002 (azul); TTJ 60 (laranja); TXA 8002 VK (verde); XR 8003 (vermelho).

Frequência acumulada
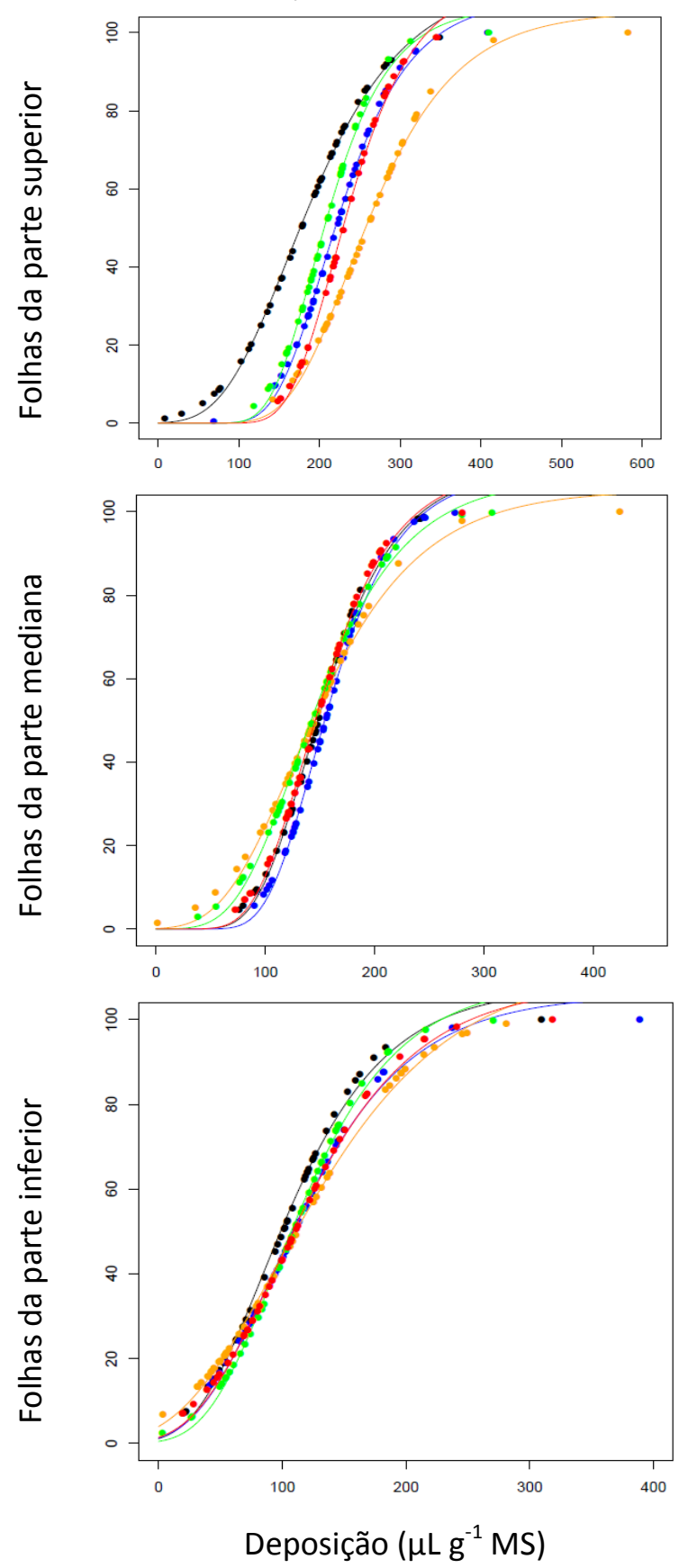

Frequência não acumulada
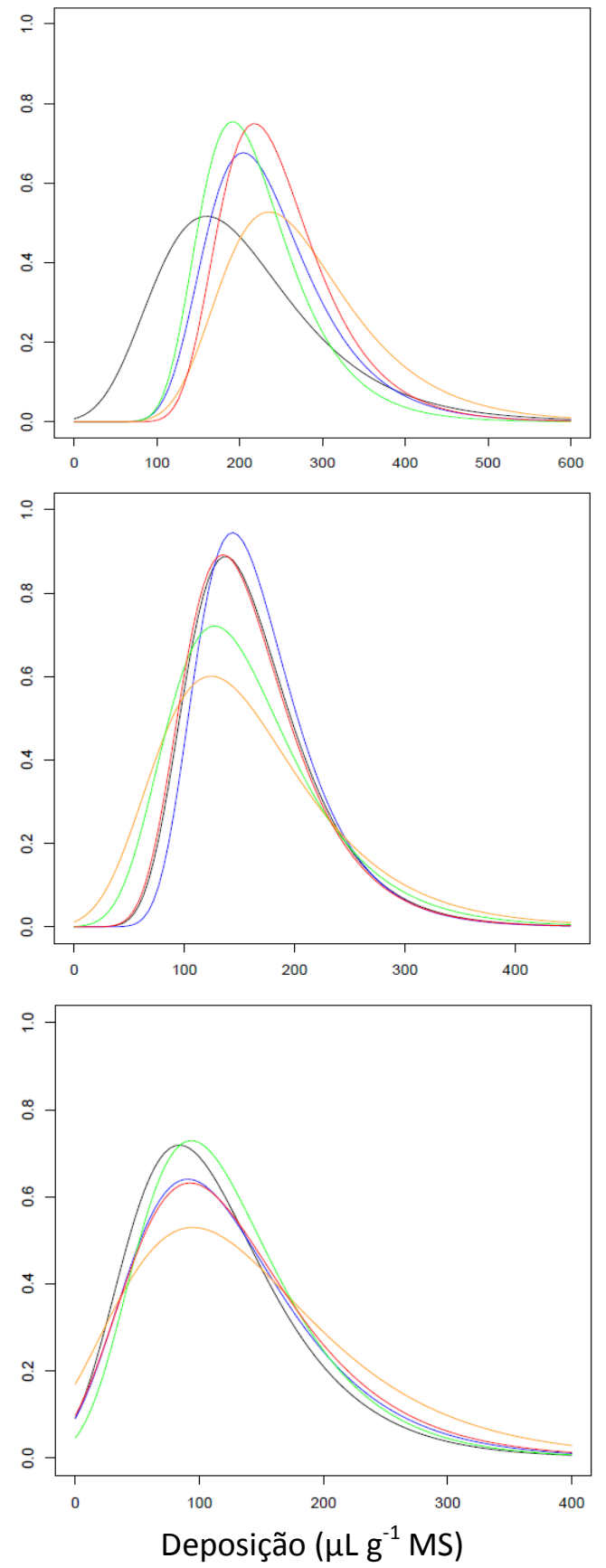

No estádio de desenvolvimento R5 quando a lavoura de soja apresentava totalmente fechada à ponta de pulverização que proporcionou a maior uniformidade de deposição nas folhas da parte superior foi a TTJ 60 com valor de parâmetro " $c$ " de 0,035. A ponta que proporcionou menor uniformidade de deposição foi a TXA 8002 apresentando o menor valor parâmetro " $\mathrm{c}$ " de 0,016 (Tabela 5). Observando a Figura 2 (folhas da parte superior), fica nítido a acentuada 
concavidade da curva que representa os valores de frequência não-acumulada pela ponta TTJ $60 \mathrm{com}$ a suave concavidade da curva proporcionada pela ponta TXA 8002. Nas folhas da parte mediana da planta de soja, as pontas de pulverização que tiveram as melhores respostas de uniformidade de deposição foram as DGTJ 11002 e XR 8003 apresentando os maiores valores do parâmetro " $c$ " de 0,030 e 0,028 respectivamente (Tabela 5 e Figura 2). Essas duas pontas mostraram ser mais eficiente em proporcionar maior uniformidade de cobertura nas folhas de posicionadas na parte mediana da planta de soja nos dois estádios (V7-8 e R5).

Nas folhas da parte inferior da soja, as pontas que tiveram os melhores valores de uniformidade de deposição foram AIXR 110025 e TXA 8002 com valores de parâmetro "c" de 0,029 .

Tabela 5. Resultados das análises de regressão das frequências acumuladas dos depósitos da pulverização no estádio R5 proporcionados pelas pontas de pulverização, utilizando ajuste do modelo de Gompertz.

\begin{tabular}{lccccc}
\hline Parâmetro da & AIXR 110025 & TXA 8002 & DGTJ 11002 & TTJ 60 & XR 8003 \\
\cline { 2 - 6 } Equação & \multicolumn{5}{c}{ Parte superior da planta } \\
\hline A & 4,67 & 4,66 & 4,73 & 4,73 & 4,68 \\
B & $-3,33$ & $-1,69$ & $-3,18$ & $-3,45$ & $-2,05$ \\
C & 0,031 & 0,016 & 0,028 & 0,035 & 0,022 \\
$\mathrm{R}^{2}$ & 0,99 & 0,99 & 0,99 & 0,99 & 0,99 \\
\hline \multicolumn{5}{c}{ Parte mediana da planta } \\
\hline A & 4,65 & 4,72 & 4,76 & 4,67 & 4,69 \\
B & $-1,90$ & $-2,00$ & $-2,22$ & $-1,65$ & $-1,99$ \\
C & 0,022 & 0,024 & 0,030 & 0,025 & 0,028 \\
$\mathrm{R}^{2}$ & 0,99 & 0,99 & 0,99 & 0,99 & 0,99 \\
\hline \multicolumn{5}{c}{ Parte inferior da planta } \\
\hline A & 4,70 & 4,70 & 4,69 & 4,66 \\
B & $-1,76$ & $-1,34$ & $-1,25$ & $-0,612$ & $-0,791$ \\
C & 0,029 & 0,029 & 0,021 & 0,017 & 0,015 \\
$\mathrm{R}^{2}$ & 0,99 & 0,99 & 0,99 & 0,99 & 0,99 \\
\hline
\end{tabular}


Figura 2. Frequência acumulada e não-acumulada dos depósitos da pulverização ( $\mu \mathrm{L} \mathrm{g}^{-1} \mathrm{MS}$ ) proporcionados por diferentes pontas de pulverização nas folhas de soja da parte superior, mediana e inferior no estádio R5. AIXR 110025 (preto); DGTJ 11002 (azul); TTJ 60 (laranja); TXA 8002 VK (verde); XR 8003 (vermelho).

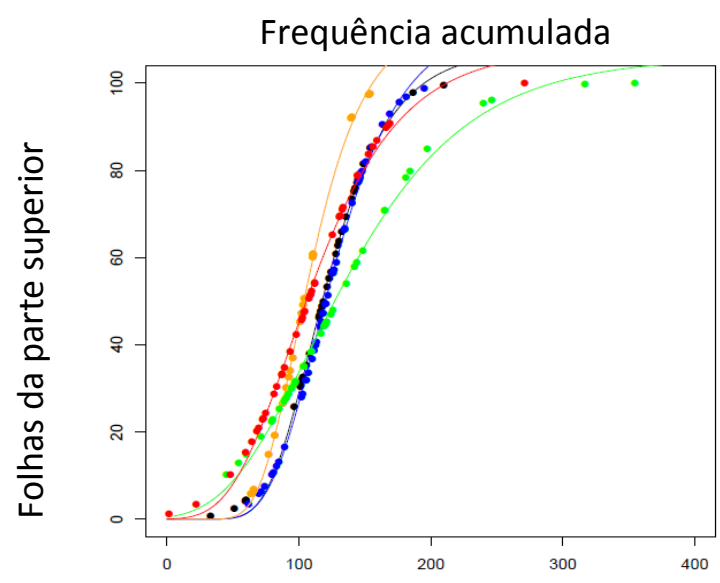
Frequência não acumulada
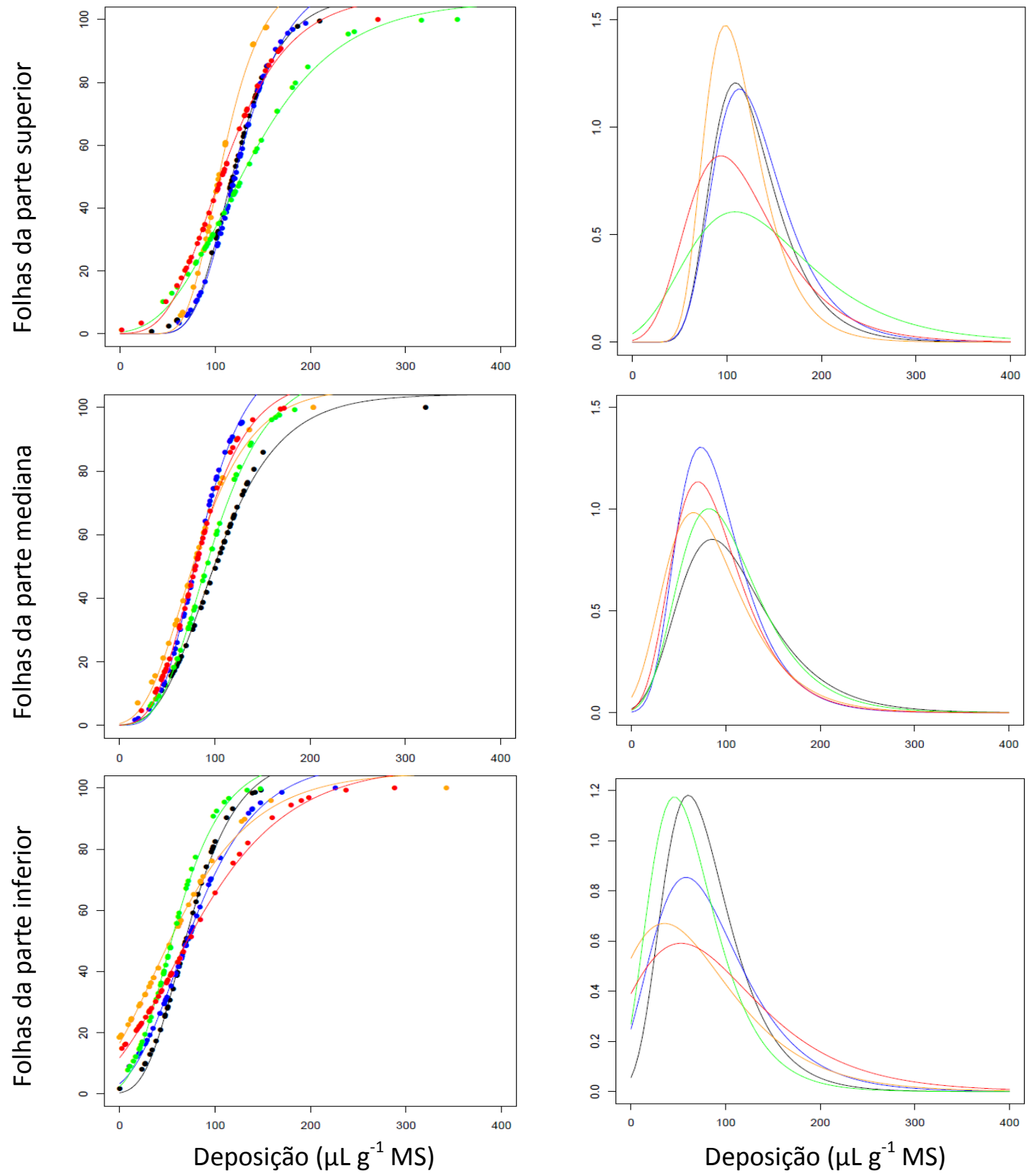

Maior uniformidade dos depósitos da pulverização no estádio de desenvolvimento V7-8 nas folhas da parte superior e mediana foi verificada pelas pontas que proporcionam gotas finas $e$ a menor uniformidade proporcionada pelas pontas que proporcionaram gotas médias. Já na aplicação realizada no estádio reprodutivo da soja (R5) maior uniformidade de deposição foram observados para as pontas que proporcionaram gotas de tamanho médio/grossa. Essas diferenças de uniformidade encontrada, provavelmente esta relacionada com o índice de área foliar (IAF) apresentado nos diferentes estádios fenológicos da cultura da soja. Quando a 
cultura apresentava menores IAF (V7-8) provavelmente as gotas maiores, após o impacto com as folhas, pode ter ocorrido o efeito rebote (recochiteamento) onde essas gotas não se aderiram nas superfícies das folhas sendo depositadas em outro lugar que não sejam nas folhas da soja. Já as gotas menores, as quais apresentam como característica maior facilidade de adesão, foram depositadas na superfície das folhas da parte superior e mediana.

Quando as plantas estavam com maior IAF (R5), gotas maiores podem ter recochiteadas após o impacto com as folhas e se depositaram em outras folhas no entorno. No geral foram encontrados resultados controversos relacionados com a uniformidade de deposição. Como mencionado anteriormente à ponta DGTJ (gota fina) mostrou maior uniformidade de depósitos da pulverização nas folhas da parte mediana da soja nos dois estádios de desenvolvimento. $O$ entendimento das pontas de pulverização que proporcionem maiores valores de deposição e uniformidade de distribuição é de grande importância na aplicação de defensivos agrícolas. Geralmente, o controle químico de insetos-pragas e doenças na cultura da soja esta correlacionado com maiores quantidades de defensivos depositados sobre o alvo de interesse que em muitos casos são as folhas de soja. Outra questão que deve ser evitada no processo de pulverização de defensivos é a contaminação ambiental que essas substâncias podem ocasionar. É sabido que gotas mais finas são mais propensas de serem carregadas pelo vento e devem ser evitadas ao máximo para minimização desses problemas. Desde que não comprometam a qualidade da aplicação como deposição e uniformidade de distribuição e consequentemente a eficiência de controle, as gotas maiores devem ser utilizadas por reduzirem contaminação de áreas não alvo.

\section{CONCLUSÃO}

No estádio de desenvolvimento V7-8 a ponta de pulverização que proporcionou maior valor de deposição nas plantas de soja foram TTJ 60, DGTJ 11002 e XR 8003. Na segunda aplicação (R5), as pontas de pulverização que proporcionaram os maiores valores de deposição nas plantas de soja foram AIXR 110025, TXA 8002 e DGTJ 110025. Maiores valores de uniformidade na parte mediana das plantas foram verificadas pela ponta DGTJ 11002.

\section{REFERÊNCIAS BIBLIOGRÁFICAS}

BAUER, F.C.; PEREIRA, F.A.R. Fitossanidade e produção agrícola. In: BAUER, F. C.; VARGAS JUNIOR, F. M. (Coords.) Produção e gestão agroindustrial. Campo Grande: Editora Uniderp, 2005. p. 23-48.

BARBOSA, M.A.; ASSUMPÇÃO, R.D. Ocupação territorial da produção e da agroindústria da soja no Brasil, nas décadas de 80 e 90. Informações Econômicas. v.31, n.1, p.7-16, 2001.

Degrande, P.E.; VIVAN, L.M. Pragas da soja Boletim de Pesquisa de Soja, J. Caju, M. M. Yuyama, S. Suzuki, and S. A. Camacho, Eds., vol. 12, p. 254, Fundação MT, Rondonópolis, Brazil, 2008. 
DERKSEN, R.C.; ZHU, H.; FOX, R.D.; BRAZEE, R.D.; KRAUSE, C.R. Coverage and drift produced by air induction and conventional hydraulic nozzles used for orchards applications. Transaction of the ASABE, v.50, p.1493-1501, 2007.

FARINHA, J. V.; MARTINS, D.; COSTA, N. V.; DOMINGOS, V. D. Deposição da calda de pulverização em cultivares de soja no estádio R1. Ciência Rural, v.39, n.6, p.1738-1744, 2009.

FEHR, W.R., CAVINESS, C.E. Stages of soybean development. Ames: lowa State University, 1977. 12p. (Special Report, 80).

FRITZ, B.K.; HOFFMANN, W.C.; CZACZYK, Z.; BAGLEY, W.; KRUGER, G.; HENRY, R. Measurement and classification methods using the ASAE S572.1 reference nozzles. Journal of Plant Protection Research, v.52, p.447-457, 2012.

CUNHA, J. P. A. R.; TEIXEIRA, M. M. Características técnicas de bicos de pulverização hidráulicos de jato plano. Revista Brasileira de Engenharia Agrícola e Ambiental, Campina Grande, v. 5, n. 2, p. 344-348, 2001.

CUNHA J.P.A.R., MOURA E.A.C, SILVA JÚNIOR J.L., ZAGO F.A. \& JULIATTI F.C. Efeito de pontas de pulverização no controle químico da ferrugem da soja. Engenharia Agrícola, v.28, p.283291, 2008.

CUNHA, J.P.A.R.; SILVA, R.A.M.; OLIVET, J.J. Nozzle and spray volume evaluation on soybean (Glycine max (L.) Merril) fungicide application. Revista de la Facultad de Agronomía, v.28, p.344-359, 2011.

GAZZIERO, D.L.P.; MACIEL, C.D.G.; SOUZA, R.T.; VELINI, E.D.; PRETE, C.E.C.; OLIVEIRA NETO, W. Deposição de glyphosate aplicado para controle de plantas daninhas em soja transgênica. Planta daninha, v.24, n.1, p.173-181, 2006.

PRADO, E.P., POGETtO, M.H.D.A., DE CERQUeIRA, D.T., RAETANO, C.G.; COSTA, S.I.D.A. Construction and practical application of a canopy opener device. Engenharia Agrícola. v.36, n.6, p.1126-1135, 2016.

R Core Team (2016). R: A language and environment for statistical computing. R Foundation for Statistical Computing, Vienna, Austria. URL <https://www.R-project.org/>

VELINI, E. D. Estudos e desenvolvimento de métodos experimentais e amostrais adaptados à matologia. 1995. 250 f. Tese (Doutorado em Agronomia) - Universidade Estadual Paulista Julio de Mesquita Filho, Jaboticabal, 1995.

VIANA, R.G.; FERREIRA, L.R.; FERREIRA, M.C.; TEIXEIRA, M.M.; ROSELL, J.R.; TUFFI SANTOS, L.D.; MACHADO, A.F.L. Distribuição volumétrica e espectro de gotas de pontas de pulverização de baixa deriva. Planta Daninha, v.28, p.439-446, 2010. 
RUAS, R.A.A. et al. Estimativa de parâmetros técnicos da tecnologia de aplicação do glyphosate no controle de Brachiaria decumbens. Ceres, v.58, n.3, p.299-304, 2011. 